\title{
Diálogos Marramao y Arroyo, Giacomo Marramao y Francesc Arroyo.
}

Israel Covarrubias

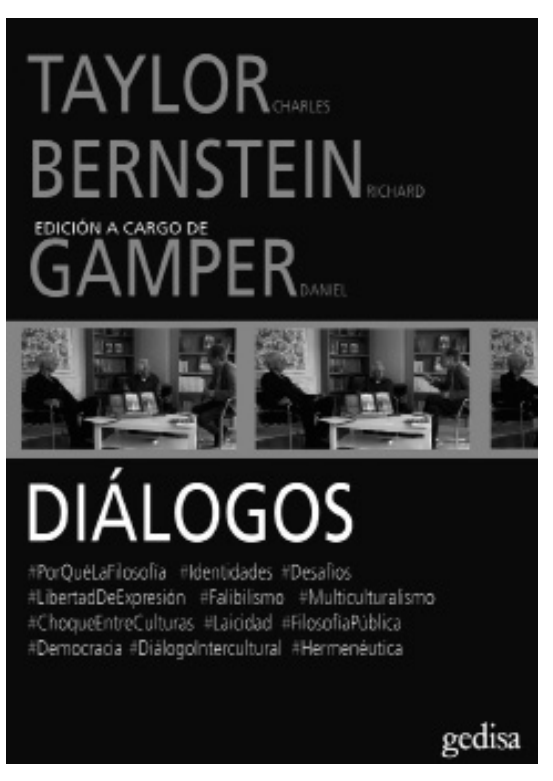

Giacomo Marranao y Francesc Arroyo, Diálogos Marranao y Arroyo. Barcelona: Gedisa, 2017.
La obra Diálogos Marramao y Arroyo, donde tiene lugar un interesante $\mathrm{y}$ por demás agudo encuentro del pensamiento entre el filósofo italiano Giacomo Marramao y el periodista español Francesc Arroyo, resulta un testimonio vivo acerca del lugar de la filosofía en el presente. La llave que abre el umbral del diálogo está determinada por una particular atención al campo de lo político, quizá la forma de filosofía más trabajada por Marramao a lo largo de su obra, comenzando con su hoy inconseguible libro Lo politico y sus transformaciones de 1979, traducido en nuestro país en 1982, en la colección Cuadernos 
del pasado y el presente de la editorial Siglo XXI. ${ }^{1}$

Es recurrente tratar "lo político" como un adjetivo que, en primera instancia, se destaca del sustantivo "la política" por la identificación de cuestiones del orden filosófico y, sobre todo, teórico: unas y otras apuntalan y reportan en el trabajo de conceptualización y problematización de las grandes cuestiones que aquejan a las sociedades, en particular a las modernas y a las contemporáneas. Lo que la obra de Marramao anuncia, además del profundo trabajo de conceptualización y reconceptualización continua en el ámbito de la filosofía política, es colocar la cuestión de lo político: "en una confrontación directa con las ciencias sociales", ${ }^{2}$ dentro del campo fronterizo de las suturas de la política, y la observación del efecto producido por las censuras que la política le otorga —bajo la forma de presión y clausura de la reflexividad de los límites - a la cuestión de lo político.

En la obra de Giacomo Marramao existe un continuo "trabajo del concepto" de lo político, que hoy puede abrir líneas de pensamiento relevantes para la filosofía y la teoría política desarrollada fuera del oficio puramente técnico, justo en la producción del pensamiento sobre la política y lo político. ${ }^{3}$ De hecho, mantener la distinción en su radical conjunción es una forma original de pensar la política de nuestros días.

Lo político supone, entre otras cosas, subrayar el papel que juega "la individualización de los puntos de ruptura", ${ }^{4}$ sea del "esencialismo", sea del neopositivismo o de la extrema obsesión por el número, como acontece con la ciencia política contemporánea. Pero también, supone

\footnotetext{
Giacomo Marramao, Lo politico y sus transformaciones (Ciudad de México: Siglo xxi Editores, 1982).

2 Giacomo Marramao y Francesc Arroyo, Diálogos Marramao y Arroyo (Barcelona: Gedisa, 2017), 25.

3 Giacomo Marramao, Pasaje a Occidente. Filosofía y globalización (Buenos Aires: Katz Editores, 2005).

4 Marramao y Arroyo, Diálogos, 31.
} 
debatir en torno a "los fenómenos de fragmentación de la soberanía y de la deslocalización de las formas de poder y de conflicto", 5 argumento que encontramos referido en Lo político y sus transformaciones, pero también está expandido, por ejemplo, en Pasaje a Occidente. Filosofía y globalización, o en Contra el poder. Filosofía y escritura, libros publicados en italiano en 2003 y en 2011, respectivamente. ${ }^{6}$

El campo de lo político se despliega en las poco más de cien páginas que componen la obra, por medio de la función que cumple en la política contemporánea, en particular con la democracia. ¿De qué trata esta relación? Por cuestiones prácticas, se puede abordar el asunto a partir de dos ejes que enuncio sintéticamente del siguiente modo: los problemas y desafíos de aquello que Marramao llama el "universalismo de la diferencia", 7 junto y a través de la cada vez más difícil conjunción del plural con el singular en la democracia —en una suerte, ciertamente impolítica y politizada al mismo tiempo, de estar "adentro y en contra" en la democracia, quizá una de las formas preponderantes de lo político en nuestras sociedades. ${ }^{8}$ Es evidente que ambas direcciones no son las únicas en la obra, pero juzgo que sí son los ámbitos que pueden revelarnos - y guiarnos - a lo largo del libro.

En muchas de las páginas del diálogo, estas dos orillas nos meten con fuerza, una y otra vez, en el corazón del problema del orden político democrático y contra-democrático, tal y como ha llegado a estas primeras dos décadas del siglo xxi: ¿qué se puede identificar?, ¿qué se debe decir?, ¿qué se puede hacer?, ¿qué es necesario objetar de las democracias realmente existentes y de las formas teóricas que tenemos a nuestra disposición para pensarlas? En suma, ¿cómo se puede

Marramao y Arroyo, Diálogos, 31.

6 Marramao, Pasaje, 231-256; Giacomo Marramao, Contra el poder. Filosofía y escritura (Buenos Aires: Fondo de Cultura Económica, 2013), 75-92.

Marramao y Arroyo, Diálogos, 43, 74.

8 La idea de estar "adentro y en contra" es de Roberto Esposito, Pensiero vivente. Origine e attualità della filosofia italiana (Turín: Einaudi, 2010), 26. 
y bajo qué punto de vista es posible interrogarnos en torno a los problemas de la democracia, como cuestiones que atañen de manera directa a la "pasión por el presente", 9 como reza el título de otro de sus libros?

La filosofía, dice Marramao, "es el arte de la pregunta, de preguntarse, el arte de la interrogación"; ${ }^{10}$ una pasión que desarrolla el trabajo del pensamiento al interrogar el presente, incluyendo a las urgencias y las exigencias del acontecimiento. Todo ello a partir de su condición de completa y abierta inactualidad, palabra-clave en la semántica de Marramao; siguiendo las huellas de Nietzsche supone más bien exige- un distanciamiento y una dislocación del tiempo al cual se pertenece: interrogarse es, pues, colocarse "en un desfase anticipador del propio tiempo". ${ }^{11}$ Agrega: "Eximirse de una consideración acerca de la actualidad es, por lo tanto, para un filósofo literalmente algo impensable, sobre todo cuando ella hace irrupción en la fisonomía de un evento traumático...". ${ }^{12}$ No se puede ser indiferente ante los "eventos traumáticos". Es una exigencia intelectual y cultural, pareciera decir Marramao. Pero no sólo frente a los eventos traumáticos de alto impacto (como lo fueron los ataques terroristas del 11 de septiembre de 2001); lo político también es una palabra fuerte desde el punto de vista sociológico y politológico. Si la intentamos colocar al interior del régimen de historicidad de nuestra condición mexicana, hic et nunc, me viene como cascada la figura de los desaparecidos y las fosas clandestinas, terrible forma de lo político, junto a la de la violencia o la radicalización de la diferencia...

En este orden de ideas, el lector podrá encontrar diversos ámbitos y flashes de discusión sobre cuestiones que atañen a lo político como: la ciudadanía,

9 Giacomo Marramao, La pasión del presente. Breve léxico de la modernidad-mundo (Barcelona: Gedisa, 2011).

10 Marramao y Arroyo, Diálogos, 51.

11 Marramao, La pasión, 176.

12 Marramao, La pasión, 176. 
el terrorismo, los nuevos autoritarismos, las guerras de religiones, la secularización (de la secularización), la técnica y la desmesura (hybris) que componen la interrogante sobre la utilidad de lo útil frente a las posibilidades del decrecimiento (dixit Serge Latouche) y la necesidad de construcción de los bienes comunes, etcétera. Para el autor este último aspecto es uno de los "asuntos centrales" de la democracia: "La condición para que haya una verdadera democracia no es sólo que se apliquen correctamente las reglas. Es imprescindible que se dé otra condición: la posibilidad del disfrute colectivo de bienes comunes materiales y otros que parecen inmateriales". ${ }^{13}$

Lo político es una forma no domesticable, abiertamente contingente - pensemos, dice Marramao, en una "ontología de lo contingente"- ${ }^{14}$ que une a las dos orillas, al universalismo de la diferencia y la aporía constitutiva del plural-singular democrático, en un nivel de inteligibilidad diferente al enumerado, aunque sea común la pretensión de empatarlos: lo que comparten es la dinamización del conflicto, los efectos que produce, así como su capacidad de transformación hacia formas cada vez más intensificadas.

En suma, lo político revela su real campo de concreción: el carácter inmanente del conflicto al interior de las sociedades democráticas. Ésta es una cuestión que viene de lejos en el pensamiento político italiano, probablemente sea a Maquiavelo a quien debemos su primera conceptualización. En este sentido, son célebres sus observaciones sobre las diferencias entre el "pueblo" y los "grandes":

Creo que los que condenan los tumultos entre los nobles y la plebe atacan lo que fue la causa principal de la libertad de Roma, se fijan más en los ruidos y gritos que nacían de esos tumultos que en los buenos efectos que produjeron, y consi-

\footnotetext{
Marramao y Arroyo, Diálogos, 101.

14 Marramao y Arroyo, Diálogos, 46.
} 
deran que en toda república hay dos espíritus contrapuestos: el de los grandes y el del pueblo, y todas las leyes que se hacen en pro de la libertad nacen de la desunión entre ambos [...] no se puede llamar, en modo alguno, desordenada una república donde existieron tantos ejemplos de virtud, porque los buenos ejemplos nacen de la buena educación, la buena educación de las buenas leyes, y las buenas leyes de esas diferencias internas que muchos, desconsideradamente, condenan, pues quien estudie el buen fin que tuvieron encontrará que no engendraron exilios ni violencias en perjuicio del bien común, sino leyes y órdenes de beneficio de la libertad pública. ${ }^{15}$

En este mismo orden de ideas, Marramao escribirá: "En la buena tradición italiana de Maquiavelo, yo estoy a favor de una democracia tumultuaria: no tenemos que tener miedo a los tumultos porque cuando no hay tumultos, cuando no hay expresión de los conflictos sociales, puede ser que acabe por producirse una ruptura imprevista". ${ }^{16}$

¿Por qué subrayar este carácter tumultuario de lo político? Porque Marramao observa los desafíos que hoy tenemos frente al "fracaso" de los dos modelos de asimilación: integración y cohesión democrática. Uno, de impronta francesa, cobra vida bajo la forma del modelo "asimilacionista republicano"; y el otro, de raigambre británica, es el "modelo multiculturalista". ${ }^{17}$ Afirma: "el modelo republicano francés $[. .$.$] presupone una escena$ pública indiferenciada. Todos somos ciudadanos y no se tienen en cuenta las diferencias de sexo, de religión, de cultura, de lengua, etcétera". ${ }^{18}$ Es decir, es un modelo con pretensión de universalización, que no sólo subsume sino que castiga las diferencias. En cambio, en el inglés "es un modelo 'mosaico' donde conviven, en apa-

\footnotetext{
15 Nicolás Maquiavelo, Discursos sobre la primera década de Tito Livio (Madrid: Alianza, 2009), 41-42.

16 Marramao y Arroyo, Diálogos, 70.

17 Marramao y Arroyo, Diálogos, 72-73.

18 Marramao y Arroyo, Diálogos, 72.
} 
riencia armónicamente, los diferentes grupos culturales. Sin embargo, cada grupo cultural permanece en una especie de isla sin comunicación con los demás, es como una mónada sin relación con las otras". ${ }^{19}$ ¿Qué tienen de problemático ambos modelos? Que el primero "promueve la indiferencia" y el segundo se sostiene mediante "una pluralidad de guetos contiguos". ${ }^{20}$

Para Marramao es el universalismo de la diferencia la forma de lo político que podría desplazar el orden de la democracia hacia nuevas maneras de construcción política, nuevas subjetividades y nuevas aventuras:

[...] tengo la impresión de que el modelo que está más cerca de mi fórmula [...] es el modelo de origen latino, romano, de la civitas. Se trata de un modelo de integración basado en la idea de orden, de Constitución y de ley universal, pero con una idea de comunidad pluricultural, con una idea plural del pueblo [...] la solución pasa por la idea de la civitas romana como un espacio jurídico y político capaz de integrar en sí mismo una pluralidad de diferencias, de gentes diferentes, con lenguajes diferentes, con religiones diferentes, con ideologías diferentes. Este modelo me parece el modelo más potente, con una condición indispensable, sine qua non: el respeto riguroso a una ley universal, válida erga omnes (para todos) [...] Tenemos que ser muy cuidadosos y no confundir el derecho a la diferencia con la diferencia en el derecho. ${ }^{21}$

Marramao es sin duda uno de los filósofos políticos más relevantes en el panorama intelectual italiano de nuestros días. Un pensador y polemólogo de "paladar fino", cuya relevancia se extiende desde hace tiempo más allá de las fronteras de la península. Por eso, le viene bien a nuestra cultura académica contar con la presencia

\footnotetext{
Marramao y Arroyo, Diálogos, 73.

20 Marramao y Arroyo, Diálogos, 73-74.

21 Marramao y Arroyo, Diálogos, 74-75.
} 
y la obra de un autor y, sobre todo, un pensador como él. Con sus libros ganamos todos. La serie de detalles e indicios que nos ofrece Diálogos Marramao y Arroyo es rica en ideas para nutrir nuestra condición presente, es también una guía de lectura para aquellos que quieran comenzar a leerlo. Ojalá que esto último sea una realidad en nuestras universidades y en todos aquellos espacios culturales preocupados y ocupados por seguir debatiendo en torno a lo político.

\section{Referencias}

Maquiavelo, Nicolás. Discursos sobre la primera década de Tito Livio. Madrid: Alianza, 2009.

Marramao, Giacomo. Lo politico y sus transformaciones. Ciudad de México: Siglo xxI Editores, 1982.

. Pasaje a Occidente. Filosofía y globalización. Buenos Aires: Katz Editores, 2005.

. La pasión del presente. Breve léxico de la modernidad-mundo. Barcelona: Gedisa, 2011. 